\title{
Entrevista ilustrada com professor Sérgio Rizo
}

\section{Illustrated interview with professor Sérgio Rizo}

\section{Sérgio Rizo}

Arquiteto e Urbanista formado pela Universidade de Brasília (1979), mestrado em Fine Arts - Pratt Institute (1990), New York, como bolsista do Conselho Nacional de Desenvolvimento Científico e Tecnológico, CNPa e Doutorado em História pela Universidade de Brasilia (2004). Professor da Faculdade de Arquitetura e Urbanismo da Universidade de Brasilia, desde 2012, atualmente é Chefe do Departamento de Projeto, Expressão e Representação. Integra o Núcleo de Estética, Hermenêutica e Semiótica do PPG-FAU. Lecionou no Departamento de Artes Visuais/ Instituto de Artes da Universidade de Brasilia de 1991 até 2012. Tem experiência na área de Artes, com ênfase em Pintura, Desenho, Anatomia Artística e Teoria e História da Arte.

Bom dia professor Sérgio Rizo, primeiramente gostaria de agradecer em nome do Núcleo de Estética e Semiótica pela disponibilidade em nos conceder essa entrevista. Para começar, podemos falar um pouco sobre sua formação e o modo com que o desenho entrou na sua vida.

Rizo - Bom dia! Bom, desde garoto, o desenho está na minha vida, como acontece com todo artista. Pelo fato de ser mais introvertido eu habitualmente cultivava minha imaginação. Eu gostava muito das revistas de quadrinhos e elas foram a minha entrada no universo da arte figurativa. Eu as devorava avidamente, vivenciando na imaginação as aventuras ilustradas com os seus heróis, damas e vilões. Nessa época, eu vivia fantasiando as coisas e o desenho veio naturalmente como um meio de expressão do meu sentir e pensar. Ao mesmo tempo, eu gostava muito de ler, ainda mais naqueles dias em que não havia as "seduções do olhar" das imagens eletrônicas atuais. Eu lia livros ilustrados e, por mínima que fosse a ilustração, eu ficava absolutamente fascinado.

Na medida em que eu fui crescendo, li dois livros importantíssimos do Monteiro Lobato: As reinações de Narizinho e Os doze trabalhos de Hércules. Em Reinações de Narizinho, eu descobri no mundo aquático do "Reino das Águas Claras" o meu interesse pela natureza. Com Os doze trabalhos de Hércules, eu via no herói o meu pai e os seus ensinamentos e eu era o Pedrinho e as suas caçadas de onças no Sítio do Picapau Amarelo. Data daí o meu encantamento com a arte grega e o mundo clássico. A referência principal do meu envolvimento com a pintura foi uma coleção de fascículos intitulada Gênios da Pintura e, com 10 ou 11 anos, eu queria copiar Rembrandt, imagina só! Aos doze anos cursei a Escola Pan-Americana de Arte, que tinha um curso por correspondência simplesmente fantástico, mais voltado para os ilustradores. Foi uma das melhores coisas que eu já tinha visto, pois também ensinava a desenhar quadrinhos. Tinha também a parte voltada para a anatomia artística, humana e comparada, que para mim representou um amor à primeira vista. Era o tempo de ouro da ilustração. 0 ilustrador tinha que saber desenhar bichos e pessoas, se não soubesse, estava fora do mercado.

O engraçado foi que os desenhos que eu mandava nos envelopes resposta iam frequentemente borrados com gotas de suor. Explico: eu adorava jogar futebol e muitas vezes ao chegar em casa das peladas ia desenhar as lições completamente suado, coisas de moleque! A partir dos quatorze anos as capas dos discos de rock e os posters norte-americanos, do tipo daqueles do Peter Max, foram outras influências importantes para mim. Quando entrei na adolescência, o sexo oposto me tirou um pouco da atenção dos estudos da arte. Mantive certa relação com a imagem, mas não me dedicava mais como antes. E aí, com 18 anos, chegou aquele sufoco: "o que eu vou fazer da minha vida?". Eu olhava para os meus amigos e eles também não estavam muito certos do que iriam fazer. E sempre tinha alguém que dizia: "vou fazer medicina, pois dá grana”. Eu pensava: "só esse negócio de grana é muito chato, quero fazer uma coisa também legal. Eu gosto de desenhar, vou fazer arquitetura". Cursar arquitetura foi para mim uma escolha instintiva por causa do meu amor pelo desenho. 


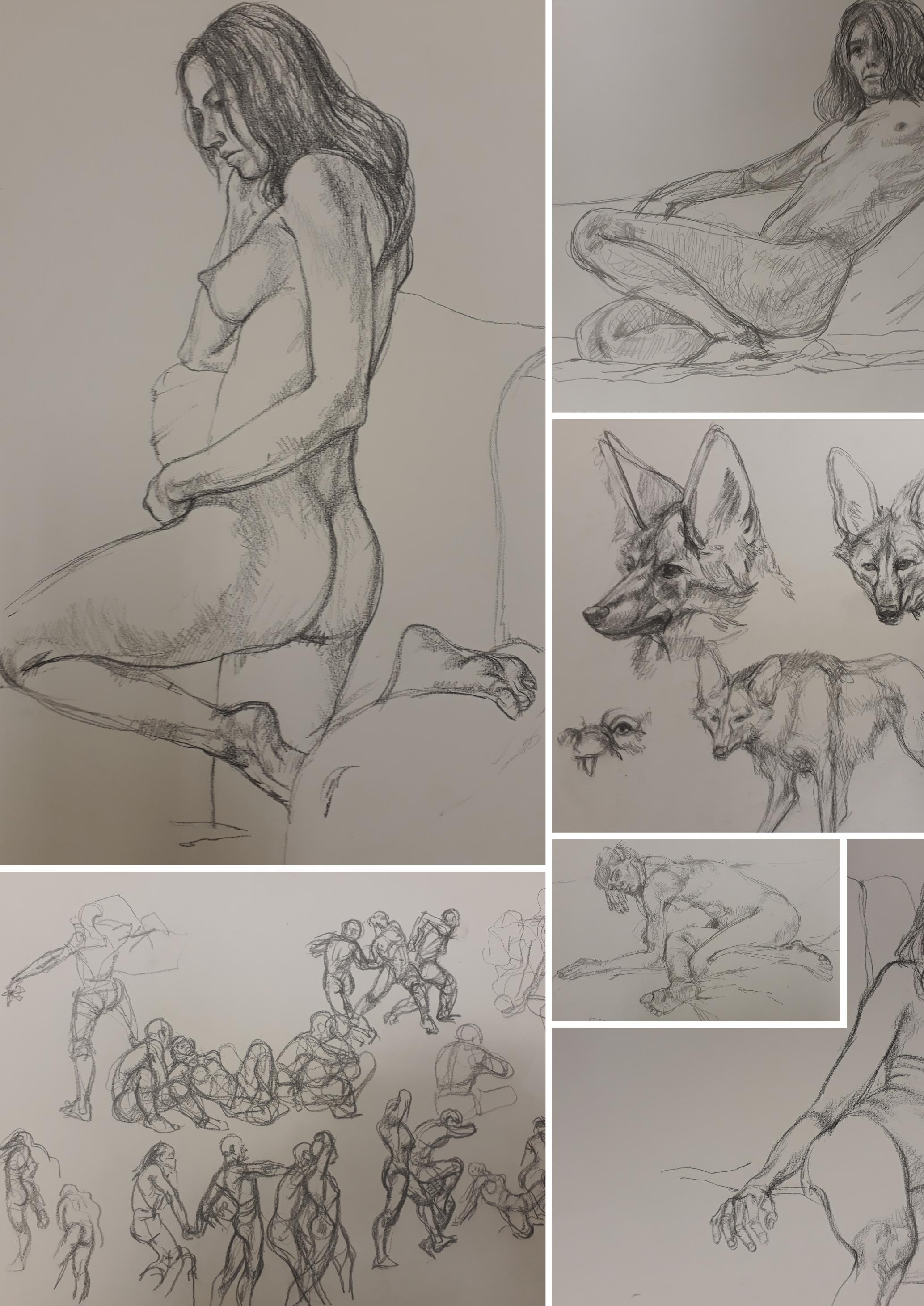


Professor Rizo, nos fale um pouco sobre suas referências: quais os artistas que mais influenciaram na sua formação?

Brasília não tem, em função da sua idade e natureza, um museu tradicional, daqueles com um razoável acervo de imagens, como o MASP em São Paulo ou o MNBA no Rio. Como não existia nenhum museu, ainda mais naqueles tempos, eu frequentava uma galeria de arte no Setor Comercial Sul do Oscar Seraphico, um conhecido da minha família e que foi um dos melhores marchands de Brasilia. Passava as tardes na sua galeria vendo as gravuras do Marcelo Grassmann, os quadros do Scliar, vendo Siron Franco, que foi uma grande referência para mim, principalmente no período dos anos 70 (é um pintor que eu admiro muito, ainda mais por ser de Goiás, que eu considero ser a minha terra). Eu via Francisco Rebolo, Fúlvio Pennacchi, Alfredo Volpi, o grupo Santa Helena e vários outros. A galeria do Oscar Seraphico foi muito importante na educação do meu olhar. Existiram os livros também como uma fonte importante de referências, lia de tudo, mas nutria uma preferência especial: os surrealistas, principalmente o Salvador Dali. Depois vieram Bosh, Bruegel e o Dürer.

Como você iniciou a sua carreira como artista e como conciliava com seu trabalho na arquitetura?

O Glênio Bianchetti, um grande artista gaúcho radicado em Brasília, tinha um curso noturno de desenho na W3 Sul que me foi indicado por um amigo em comum. Com ele, fiz dois anos de desenho de modelo vivo e dois anos de pintura, enquanto cursava arquitetura na UnB. Eu aprendi muito com esse curso. O Glênio era um professor muito criterioso, sentava com o aluno e corrigia os desenhos, como eu também faço com meus alunos. Foi um professor muito importante para a minha formação, além de um amigo querido.

Quando me formei em arquitetura, me casei e passei a viver essa vida de sobrevivência. Naquela época, as empresas contratavam as pessoas por indicação, e assim eu fui trabalhar com o Jorge Guilherme Francisconi, notório arquiteto e urbanista da UFRGS. Trabalhei com ele na Empresa Brasileira de Transportes Urbanos, ótima experiência em planejamento urbano, mas que começou a prejudicar minha ambição de ser artista. Nos anos 80 , foi a primeira vez que eu fui visitar alguns dos melhores museus da Europa como o Louvre, a National Gallery, o Rijksmuseum, o Prado e outros. Depois dessa viagem, voltei empolgado e decidido a me dedicar à arte. Era um período em que eu estava muito insatisfeito com meu trabalho, não por não gostar de urbanismo, mas por insatisfação de ver meus colegas seguirem na carreira da arte e eu não. Obtive então uma bolsa de mestrado do CNPq para estudar desenho e pintura no Pratt Institute em Nova lorque. Pedi demissão, entreguei o meu apartamento funcional e fui. Vendi tudo o que eu tinha. Fui para ficar 3 anos. Por sorte, tinha um tio lá que me apresentou para muita gente. Naquela época, eu vendia quadros lá como nunca havia vendido no Brasil. Eram pessoas conhecidas, casais jovens que gostavam de arte e tinham dinheiro. Mas eu também fazia coisas que eu não faria hoje. Aconteceu uma vez de eu ter que virar duas noites seguidas para finalizar uma encomenda, depois carregar o quadro enorme dentro de um metrô em horário de pico, sair na rua com o quadro numa ventania forte, correndo o risco de rasgar, e por fim, tive que subir 27 andares de escada para entregar a obra (risos). Depois dessas experiências, passei a dizer para os compradores: "ou você pega no meu estúdio, ou nada feito". Nova lorque representou uma experiência ímpar. Nos anos em que eu estudei lá, amadureci muito como artista, na vivência cultural de uma metrópole que permanece como um dos mais importantes e intensos centros produtores de arte do mundo. Tive a oportunidade de ver muita coisa boa, exposições inesquecíveis, como a retrospectiva do Picasso e Braque no MoMA, as galerias descoladas do SoHo, as aulas de anatomia avançada no Pratt com o Sal Montano, peças de teatro 


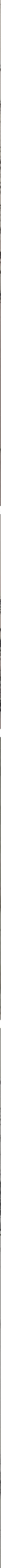


e dança contemporânea, filmes experimentais em sessões de lançamento especiais, recitais de música, enfim, tudo o que acontece numa grande cidade como essa. Muito importante também, além das aulas no Pratt, foi eu ter visitado frequentemente o Metropolitan para desenhar e estudar o seu impressionante acervo. Pude então, consolidar o meu aprendizado figurativo. Mais ainda, me envolvi com o expressionismo abstrato norte- americano dos anos 50, e o pintor Willem de Kooning foi a minha influência principal.

De que modo a experiência da docência te ajudou como artista e como vocêvêo ensino das artes em Brasilia hoje?

Quando retornei ao Brasil não pensava em lecionar. Estava com a ideia de ser unicamente artista. Mas ser artista que precisa e vive do mercado, na nossa conjuntura, é uma coisa terrível. Coincidentemente, após uma exposição individual que fiz na Galeria Performance, fui convidado para lecionar no Departamento de Artes Visuais do Instituto de Artes da UnB, como professor substituto. Comecei dando aulas de modelo vivo. Eram alunos que se interessavam pelo desenho, e acima de tudo, pelo desenho da figura humana. Acabei me apaixonando pelo ensino e resolvi abraçar a carreira acadêmica. Com o tempo, encontrei na professora Yolanda Galindo da medicina a parceira ideal para o ensino da anatomia artística. Criamos uma disciplina em conjunto que resultou numa experiência fantástica! Depois de um tempo, os professores que eu mais me identificava no IdA se aposentaram. Com isso, o discurso começou a mudar, e o desenho e a técnica passaram a não ter a importância devida. Penso que a técnica, o domínio do métier, é fundamental para todo artista que se dedique a pintura, ao desenho, a gravura e a escultura. É o que se pode ensinar. Esse tipo de arte é um ofício, um artesanato, como consta no brilhante texto do Mário de Andrade intitulado "O artista e o artesão". 0 ensino do desenho me conscientizou da sua importância como uma técnica capaz não só de formalizar um pensamento plástico, mas de dar expressão própria e pessoal à obra do artista, seja ele um desenhista, um pintor, um escultor ou um gravador.

Depois de um período eu quis voltar para a FAU, desta feita como professor e têm sido muito interessante, pois as minhas experiências lecionando nas artes se somaram a experiência de arquiteto. Passei a ter contato com outros artistas e professores, como o Reinaldo Guedes, a Neuza Cavalcante, entre outros. Encontrei um ambiente estimulante e receptivo ao ensino do desenho. Voltei para a arquitetura trazendo a bagagem do conhecimento do corpo através do desenho. Esse saber tem uma longa tradição histórica, data do vínculo do corpo com a coluna arquitetônica. O desenho é essencial também para o arquiteto, tanto em termos de conceito quanto em termos da prática propriamente dita. Suas múltiplas técnicas agora envolvem novos desafios com a utilização computacional, novas maneiras de se conceber projetos. É de fato fascinante constatar as novas possibilidades que surgem nessa área. Mas o desenho à mão livre permanece indispensável. É a mola mestra que articula o complexo sistema de representação do raciocínio geométrico e da forma sensível. Desenhar é pensar com o corpo.

Na produção artística, a inspiraçãoé um fator determinante?

Rizo - Com certeza! Se me colocam para desenhar todo dia, na obrigação, eu fico louco! Eu trabalho com inspiração. A inspiração acontece muito quando eu estou envolvido com alguma leitura. Sou daqueles artistas que necessitam de um estímulo literário constante. A leitura é o alimento da imaginação que, por sua vez, é a rainha das faculdades, como bem dizia o Baudelaire. A minha tese de doutorado, por exemplo, me inspirou muito, pois durante quatro anos eu olhei para a questão escatológica do céu e do inferno. Estudei a Divina Comédia de Dante e o Paraíso Perdido de Milton, dois clássicos mundiais. Até hoje me nutro das imagens dessas leituras. Mas não só a leitura me provoca a imaginação. Sou bem eclético e aberto às influências culturais, muita coisa me inspira: cinema, música, dança... 

ARTIGOS

( 
